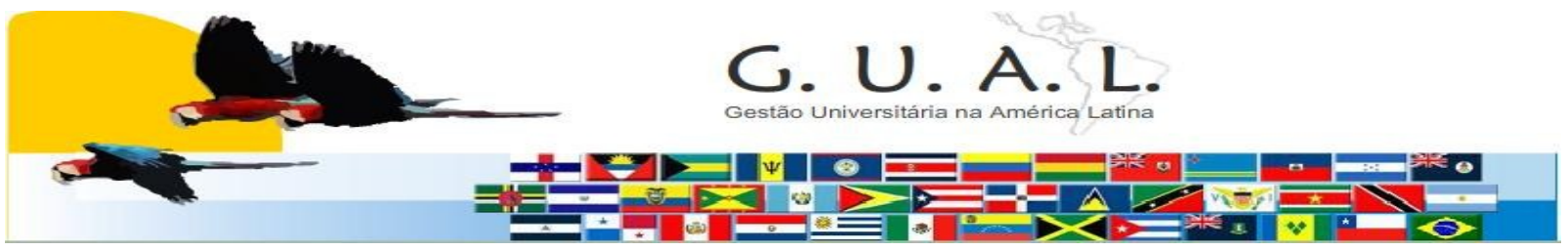

ISSN 1983-4535

\title{
ANÁLISE DOS RECURSOS PÚBLICOS APLICADOS NO RESTAURANTE UNIVERSITÁRIO DE UMA INSTITUIÇÃO FEDERAL DE ENSINO SUPERIOR
}

\author{
Francisca Aparecida de Souza, Mestre \\ Universidade de Brasília \\ fsouza@unb.br \\ César Augusto Tiburcio Silva, Doutor \\ Universidade de Brasilia \\ cesartiburcio@unb.br
}

\begin{abstract}
RESUMO
O objetivo do estudo é a análise dos recursos públicos aplicados no Restaurante Universitário de uma Instituição Federal de Ensino Superior e a verificação da opinião dos usuários do serviço de alimentação. É um estudo de caso, que envolveu a pesquisa documental de relatórios dos sistemas de informações da instituição e do Sistema de Informações da Administração Financeira do Governo Federal. Foi apurado e analisado o resultado financeiro, o custo unitário da refeição, a evolução do funcionamento do restaurante e a verificação da satisfação de seus usuários. Os resultados mostram uma atividade deficitária o que evidencia dependência financeira de recursos públicos federal, além dos gerados internamente pela instituição. No período analisado, foram aplicados $\mathrm{R} \$ 42,1$ milhões no restaurante, sendo que a receita gerada pelo restaurante foi de $\mathrm{R} \$ 6,4$ milhões. A opinião dos usuários, verificada por meio de questionário, evidencia a satisfação da maioria em relação à "qualidade do alimento" e "preço da refeição". O resultado do teste estatístico do quiquadrado- $\chi^{2}$, considerando os respondentes que têm bolsa alimentação, denota-se a associação significativa $(\mathrm{P}=0,001)$ entre a "qualidade do alimento" e a "variedade do cardápio".
\end{abstract}

Palavras-chave: Recursos públicos. Restaurante universitário. Usuários. 


\section{ANÁLISE DOS RECURSOS PÚBLICOS APLICADOS NO RESTAURANTE UNIVERSITÁRIO DE UMA INSTITUIÇÃO FEDERAL DE ENSINO SUPERIOR}

\section{INTRODUÇÃO}

Os recursos públicos destinados às Instituições Federais de Ensino Superior (IFES) em 1994 representavam 0,91\% do PIB brasileiro; em 2002 este percentual chegou a 0,64\%, redução de 30\%. Enquanto isso, no mesmo período, as matrículas nessas instituições aumentaram 37\% (SGUISSARDI, 2006). Diante disso, pode-se afirmar que, nesse período, a proporção dos recursos públicos destinados à educação e o aumento da demanda pelo ensino superior foram inversamente proporcionais, pois à medida que a busca por vagas nas IFES aumentava, os recursos a elas destinados eram reduzidos. Além disso, observava-se a proliferação de instituições de ensino superior do setor privado. Em 1991 foram ofertadas 516.663 vagas no ensino superior; e em 2005 foram 2.429.737, um aumento de 370,28\%. No entanto, $88 \%$ dessas vagas estavam em instituições particulares e, apenas cerca de $5 \%$ do total de vagas ofertadas em 2005 estavam em instituições federais (INEP, 2007).

A maior parte dos recursos destinados a manter as IFES é proveniente do Governo Federal; no entanto, esses recursos são considerados insuficientes para suprir a real necessidade de manutenção e desenvolvimento institucional. Sendo assim, algumas IFES têm buscado gerar recursos por meio de prestação de serviços remunerados (QUINTANA; SAURIN, 2005). Essa forma alternativa de financiamento tem compensado a redução de recursos públicos disponíveis para outras despesas correntes e investimentos destinados às IFES, uma vez que, a maior parcela do orçamento público é direcionada ao orçamento de pessoal e encargos sociais.

O estudo realizado por Marques e Corbucci (2003), sobre as fontes de financiamentos das IFES, encontrou que estas instituições têm mostrado potencial para gerar recursos próprios. Marques e Velloso (2005, p.667) citam o caso de uma destas instituições e afirma que “...as outras despesas correntes (...), complementares às de pessoal, e indispensáveis para manutenção e expansão da universidade, vêm sendo cada vez mais dependentes de recursos de arrecadação própria."

Diante disso, a arrecadação própria mostra-se importante no contexto orçamentário das universidades públicas, pois promove a manutenção e o desenvolvimento institucional. Esta fonte de recursos, provenientes da prestação de serviço remunerada à sociedade, tem sido usado para manter alguns serviços oferecidos à comunidade acadêmica e que não possuem orçamento suficiente para tal.

Rev. GUAL., Florianópolis, v.4, n. 2, p.01-28, mai/ago. 2011 


\section{ANÁLISE DOS RECURSOS PÚBLICOS APLICADOS NO RESTAURANTE UNIVERSITÁRIO DE UMA INSTITUIÇÃO FEDERAL DE ENSINO SUPERIOR}

Um dos serviços mantidos por algumas IFES refere-se à alimentação dos discentes, servidores e docentes, geralmente realizada por um restaurante. Em várias IFES a manutenção deste restaurante é feita com recursos do Tesouro, responsável pelo aporte orçamentário da despesa de pessoal e encargos sociais dos servidores do quadro permanente, além de outros custos de manutenção das instalações, e dos recursos gerados internamente. Em tais situações, mantém-se um subsídio ao restaurante em virtude da diferença existente entre o preço praticado e o custo necessário ao desenvolvimento operacional das atividades.

Diante do contexto, o objetivo desse estudo é a análise dos recursos públicos aplicados no restaurante universitário (RU, a partir de agora) de uma Instituição Federal de Ensino Superior, bem como verificar a opinião dos usuários do serviço de alimentação. Para alcançar o objetivo pretendido foi necessário apurar o resultado financeiro, o custo unitário da refeição, analisar a evolução do funcionamento do restaurante no período estudado, bem como verificar a opinião dos usuários do serviço de alimentação.

Espera-se que esse trabalho possa contribuir para a divulgação da aplicação de recursos públicos.

O trabalho está divido em cinco seções. Após a introdução são abordados os aspectos da apuração de resultado no setor público e os estudos desenvolvidos sobre o resultado nas IFES. Na seção três é apresentada a metodologia que norteou a pesquisa. A apresentação e análise dos dados estão na seção quatro. A seção cinco traz as considerações finais.

\section{APURAÇÃO DE RESULTADO NO SETOR PÚBLICO}

A apuração de resultado na contabilidade pública obedece às diretrizes orçamentárias, sendo que, os dados orçamentário-financeiros das entidades governamentais são armazenados no Sistema de Informações da Administração Financeira do Governo Federal (SIAFI), que é o instrumento de controle orçamentário, financeiro e patrimonial, no qual as receitas são lançadas pelo regime de caixa, e as despesas pelo empenho (BRASIL, 2007d), denominado de regime misto. O Art. 58 da Lei 4.320/64 define o empenho como sendo "o ato emanado de autoridade competente que cria para o Estado obrigação de pagamento, pendente ou não de implemento de condição" (BRASIL, 2007c).

De acordo com o Art. $9^{\circ}$ da Resolução 750/93 do Conselho Federal de Contabilidade (CFC, 2007), o princípio contábil da competência estabelece que as despesas e as receitas

Rev. GUAL., Florianópolis, v.4, n. 2, p.01-28, mai/ago. 2011 


\section{ANÁLISE DOS RECURSOS PÚBLICOS APLICADOS NO RESTAURANTE UNIVERSITÁRIO DE UMA INSTITUIÇÃO FEDERAL DE ENSINO SUPERIOR}

devam ser incluídas na demonstração de resultado no período em que ocorrem, independentes do recebimento ou pagamento, e quando se correlacionam. Dessa forma, vê-se que o sistema de informação do governo não propicia a apuração e a avaliação do resultado pela eficácia e eficiência, uma vez que, a confrontação da receita e da despesa não considera os recursos consumidos, mas a despesa empenhada.

Segundo Moura (2003a), a sistematização dos procedimentos contábeis adotados pela contabilidade pública diz respeito à arrecadação e à utilização dos recursos públicos, voltadas para a prestação de contas; no entanto, não existe orientação quanto aos registros e à evidenciação contábil, de forma que os usuários da informação possam avaliar ou tomar decisões com segurança. A confrontação das receitas e despesas, respeitando o princípio da competência, quando aplicada às áreas produtivas da administração, seja ela pública ou privada, permite a elaboração de informações relevantes à tomada de decisão, pois possibilita ao gestor conhecer o custo despendido para a produção de bens e serviços.

De acordo com o artigo 74 da Constituição Federal do Brasil (BRASIL, 1988), o governo deve “...avaliar os resultados, quanto à eficácia e eficiência, da gestão orçamentária, financeira e patrimonial nos órgãos e entidades da administração federal, bem como da aplicação de recursos públicos por entidades de direito privado". Essa premissa legal mostra a necessidade de a administração pública apurar os resultados dos programas de acordo com os insumos que realmente foram utilizados, objetivando demonstrar um resultado mais próximo da realidade. No entanto, segundo Moura (2003b), o SIAFI não está preparado para receber o lançamento da despesa quando da real utilização. O dispositivo legal (Constituição Federal do Brasil de 1988) e outros estudos indicam a necessidade da administração pública possuir um sistema de contabilização de custos que permita a análise da eficiência, na utilização dos recursos disponíveis para execução dos programas de governo.

\subsection{Apuração de resultado nas IFES}

As instituições federais de ensino superior fazem parte da administração indireta do governo federal. Por serem unidades administrativas federais, gestoras de recursos, as IFES apuram e avaliam o resultado de acordo com os dados disponibilizados pelo SIAFI, considerando no resultado as despesas empenhadas. No entanto, estudos têm sido desenvolvidos no sentido de aprimorar a apuração do resultado de recursos públicos aplicados

Rev. GUAL., Florianópolis, v.4, n. 2, p.01-28, mai/ago. 2011 


\section{ANÁLISE DOS RECURSOS PÚBLICOS APLICADOS NO RESTAURANTE UNIVERSITÁRIO DE UMA INSTITUIÇÃO FEDERAL DE ENSINO SUPERIOR}

a essas instituições (CRUZ; DIAZ; LUQUE, 2004; MORGAN, 2004; GIMÉNEZ; MARTÍNEZ, 2005). Segundo Psacharopoulos (1996), trabalhos desenvolvidos na área da economia da educação contribuem para a política de decisões educacionais, sendo que as pesquisas voltadas para a análise da eficiência de recursos ocupam o segundo lugar no nível de importância.

Com a expansão das matrículas nas IFES e a escassez dos recursos transferidos pelo Ministério da Educação e Cultura (MEC) (MARQUES e VELLOSO, 2005), trabalhos que abordam os instrumentos que permitam a avaliação da eficiência dos recursos alocados na educação têm sido desenvolvidos. Um exemplo deste tipo de estudo foi desenvolvido por Cruz, Diaz e Luque (2004) na Universidade de São Paulo, no qual foi proposta uma metodologia de avaliação de custos nas universidades públicas, em que se avalia a economia de escala e de escopo, por meio da estimação da função custo multi-produto: ensino de graduação, pós-graduação, títulos de pós-graduação e publicações. O resultado alcançado indicou que o modelo universidade de pesquisa, onde se produz ensino e pesquisa é o mais eficiente em termos de custos.

Giménez e Martínez (2005) apresentaram um modelo para a análise da eficiência dos custos por departamento, que pode ser usado para determinar o nível de redução de custos e da melhoria na produção e na qualidade. O estudo empírico foi aplicado na Universidade Autônoma de Barcelona na Espanha, onde os resultados demonstraram que os custos dos departamentos poderiam ser reduzidos em média 13,46\% no longo prazo.

Gonzalez (2003) comparou o sistema de acompanhamento em compras e da logística do RU da Universidade Estadual de Londrina com o sistema de uma empresa privada. Após a realização das observações, foi possível concluir que o sistema utilizado pela empresa privada é mais completo, enquanto o sistema utilizado pelo RU é informal. Já em relação à logística, no RU foram verificadas falhas na forma de concepção e de aplicação, ocasionando desvios e perdas de recursos públicos.

As restrições orçamentárias enfrentadas pelas universidades têm resultado em uma nova e mais complexa estrutura operacional, o que exige novos instrumentos administrativos capazes de prover as instituições com ferramentas para alocar recursos escassos de forma eficiente (GIMÉNEZ E MARTÍNEZ, 2005). De acordo com Brown e Gamber (2002), para a

Rev. GUAL., Florianópolis, v.4, n. 2, p.01-28, mai/ago. 2011 


\section{ANÁLISE DOS RECURSOS PÚBLICOS APLICADOS NO RESTAURANTE UNIVERSITÁRIO DE UMA INSTITUIÇÃO FEDERAL DE ENSINO SUPERIOR}

sustentação de uma estrutura financeira saudável, a administração deve ter amplo conhecimento dos fatores externos e internos que afetam a estrutura de custos da instituição.

A apuração do custo dos bens e serviços na administração pública permite a avaliação da eficiência e eficácia nas ações do governo. Morgan (2004) desenvolveu um modelo para apuração do custo aluno por instituto/faculdade na Universidade de Brasília, considerando o custo da depreciação, o princípio da competência e o valor do dinheiro no tempo. A partir disso, esta instituição tem aprimorado a metodologia com a apuração do custo para outras unidades da universidade, ou com a melhoria do cálculo através da incorporação de novos dados. Segundo Morgan (2004), a apuração do custo é necessária para o gerenciamento adequado dos recursos disponíveis às IFES.

\section{METODOLOGIA}

$\mathrm{Na}$ produção de pesquisa científica é necessária a definição da metodologia, que determinará os procedimentos necessários para que os objetivos sejam alcançados. Sendo assim, é necessário o delineamento das técnicas e métodos a serem adotados.

Trata-se de um estudo de caso desenvolvido no RU de uma IFES. Segundo Martins (2006), a produção de uma pesquisa empírica em que se investiga um fenômeno dentro de um contexto da vida real é denominada de estudo de caso.

A realização da pesquisa envolveu a análise documental de relatórios dos sistemas de informações desta universidade, do Governo Federal e demais documentos da instituição que permitiram o desenvolvimento e as conclusões do trabalho. Desse modo, os relatórios dos custos/despesas de salários e encargos, materiais diretos e indiretos, limpeza, segurança, energia elétrica, água e telefone, a depreciação, reformas, bem como a receita gerada pela venda da refeição foram extraídos dos sistemas de informações utilizados pela instituição (Sistema de Pessoal; Sistema de Cadastro de Prestadores de Serviços; Sistema de Compras; Sistema de Patrimônio; Sistema de Informação do RU) e do Sistema Integrado de Administração Financeira do governo federal (SIAFI), denominadas de despesas correntes e de capital.

O resultado financeiro do RU foi apurado no período de 01/01/2000 a 31/12/2006. Considerou-se um misto de regime de competência e caixa, ou seja, a receita arrecadada está incluída no resultado pelo regime de caixa, desconsiderando a transferência de propriedade,

Rev. GUAL., Florianópolis, v.4, n. 2, p.01-28, mai/ago. 2011 


\section{ANÁLISE DOS RECURSOS PÚBLICOS APLICADOS NO RESTAURANTE UNIVERSITÁRIO DE UMA INSTITUIÇÃO FEDERAL DE ENSINO SUPERIOR}

pois há casos em que se realiza o caixa, no entanto, a refeição é servida meses depois. Como o coeficiente de correlação entre a receita arrecadada e a quantidade de refeições servidas é de 0,98 , acredita-se que esse procedimento não produz diferenças relevantes no resultado do período.

Os custos/despesas estão lançados pelo regime de competência, com a exceção para o material de consumo, que devido a não disponibilidade da informação no período de apuração do resultado considerou o valor empenhado. Acredita-se que o tratamento do material de consumo não tenha prejudicado a análise uma vez que existe uma correlação positiva entre os materiais de consumo e quantidade de refeições servidas de 0,92 .

A apuração está em Real, considerando o valor do dinheiro no tempo, os dados foram atualizados pelo índice INPC/IBGE. A escolha desse indicador se justifica por retratar a variação dos preços no varejo.

A coleta dos dados, que permitiu inferir a cerca da opinião dos usuários do restaurante, foi por meio de questionário, que contém dezessete questões fechadas e uma aberta. Foi utilizada a escala tipo Likert: 1- Muito insatisfeito; 2- Insatisfeito; 3- Indiferente; 4- Satisfeito; 5- Muito satisfeito. Segundo Martins (2006), este tipo de escala muito utilizada em investigação social; foi desenvolvida por Rensis Likert, e trata-se de um conjunto de afirmações que qualificam positivamente ou negativamente o objeto que está sendo medido. Foram aplicados 619 questionários aos usuários no segundo semestre de 2006, considerando que, no ano de 2006, o Restaurante Universitário serviu em média 3.444 mil refeições diariamente, a percentagem estimada de usuários é de $18 \%$ com intervalo de confiança de 0,153 a $0,207, \alpha=0,05$.

A amostra foi selecionada de forma aleatória simples, de modo que cada um dos respondentes tenha igual probabilidade de figurar na amostra, e a seleção de um membro da população não afeta a chance de qualquer outro membro. Dessa forma, os respondentes foram abordados na porta do restaurante e em outros lugares do Campus da instituição sem que se tenha havido preferência na escolha.

Com base nos dados coletados por meio dos questionários, foi realizado teste estatístico com o objetivo de verificar se as divergências entre as freqüências observadas e esperadas são estatisticamente significantes ou não. Para tanto, foi aplicado o modelo estatístico não paramétrico qui-quadrado- $\chi^{2}$. Segundo Stevenson (2001), este teste não exige

Rev. GUAL., Florianópolis, v.4, n. 2, p.01-28, mai/ago. 2011 


\section{ANÁLISE DOS RECURSOS PÚBLICOS APLICADOS NO RESTAURANTE UNIVERSITÁRIO DE UMA INSTITUIÇÃO FEDERAL DE ENSINO SUPERIOR}

que a amostra seja distribuída normalmente, mas que as variáveis sejam qualitativas e apresentadas em forma de categorias; no entanto, o teste qui-quadrado- $\chi^{2}$ exige que as freqüências esperadas em cada categoria não sejam inferiores a 5; nesses casos, foi utilizado o teste exato de Fisher, uma vez que a probabilidade de erro é menor. A análise desse teste é igual a do qui-quadrado- $\chi^{2}$. O nível de significância utilizado nos testes é $\alpha=0,05$.

\section{APRESENTAÇÃO DOS DADOS E ANÁLISE DO RESULTADO}

O RU é aberto a toda a comunidade acadêmica e aos visitantes, funcionando de segunda a sexta-feira e oferecendo dois tipos de cardápios no almoço e no jantar: vegetariano e comum. As refeições são servidas nos seis refeitórios localizados no prédio do RU, mas excepcionalmente fornece marmitas aos alunos, além de disponibilizar o seu espaço do restaurante para eventos, tais como congressos, encontros e outros.

\section{Análise da evolução do funcionamento do restaurante/Preço da refeição e Programa bolsa-alimentação}

Em 1995, foram criados quatro grupos de usuários (Tabela 1), os preços estipulados em 1996 vigoram em 2006, com exceção para o grupo de visitante. Em 2005 foi realizado um estudo preliminar onde se apurou um custo de $\mathrm{R} \$ 8,17$ por refeição. Em virtude desta informação, a IFES aumentou o preço de $\mathrm{R} \$ 2,50$ para $\mathrm{R} \$ 5,00$.

Tabela 1- Preços da refeição no RU (R\$)

\begin{tabular}{lcc}
\hline \multicolumn{1}{c}{$\mathbf{1 9 9 5}$} & Preços no ano & Preços em 2006 \\
\hline Grupo I - Alunos carente & 0,60 & 1,39 \\
Grupo II - Aluno semicarente & 1,50 & 3,48 \\
Grupo III - Professor, servidor e demais alunos & 2,50 & 5,80 \\
Visitante & 3,50 & 8,12 \\
\hline \multicolumn{1}{c}{$\mathbf{1 9 9 6}$} & 0,50 & 1,00 \\
\hline Grupo I - Aluno carente & 1,00 & 2,00 \\
Grupo II - Aluno semicarente & 2,50 & 5,00 \\
Grupo III - Professor, servidor e demais aluno & 2,50 & 5,00 \\
Visitante & 5,00 \\
\hline \multicolumn{2}{c}{$\mathbf{2 0 0 5}$} & 5,29 \\
\hline Visitante & Fonte: Elaboração própria, com base nos dados do RU e Relatório da Comissão para \\
\hline reexame dos critérios de julgamento para a Bolsa de Alimentação no RU. Valores \\
atualizados pelo INPC-IBGE para dez.2006.
\end{tabular}

Rev. GUAL., Florianópolis, v.4, n. 2, p.01-28, mai/ago. 2011 


\section{ANÁLISE DOS RECURSOS PÚBLICOS APLICADOS NO RESTAURANTE UNIVERSITÁRIO DE UMA INSTITUIÇÃO FEDERAL DE ENSINO SUPERIOR}

O programa bolsa-alimentação é direcionado ao aluno de baixa renda, sendo assim, para ser beneficiário é preciso passar por seleção realizada por meio de estudo socioeconômico e ser identificado como aluno carente ou semicarente, $\mathrm{O}$ estudo é realizado por uma diretoria da IFES.

O percentual de beneficiários do programa bolsa-alimentação em relação ao número de alunos (graduação, mestrado e doutorado) matriculados na instituição é em torno de 11\%. Em 2000, a quantidade de beneficiários representava 10,90\% dos alunos matriculados (21.299); em 2006, esse percentual manteve-se dentro da faixa dos 10,92\% para um total de 25.213 alunos matriculados, e em 2005, o percentual chegou a $11 \%$.

\section{Quantidade de refeições servidas e público pagante}

Em 2000, foram servidas 285.189 mil refeições no almoço e jantar, uma média de 2.665 mil refeições diárias; já em 2006, foram 730.240 mil, em média 3.445 mil refeições diariamente. Denota-se que a quantidade de refeições servidas evoluiu $156,05 \%$, enquanto o público pagante cresceu 136,41\%, se comparado 2000 com 2006 (Tabela 2). Essa diferença deve-se ao fato do surgimento, em 2003, da nova categoria de usuários denominada de renúncia de receita ${ }^{1}$; nesse caso, o subsídio chega a $100 \%$ do valor da refeição.

As refeições fornecidas a todos os servidores do Restaurante e alguns da IFES são totalmente isentas. Em relação aos funcionários do RU, não foi sempre assim; em 2000 os funcionários do RU pagavam $\mathrm{R} \$ 15,00$ ou $\mathrm{R} \$ 10,00$ por mês, de acordo com o salário; a partir de 2001 passaram a pagar $\mathrm{R} \$ 15,00$ por mês. Em 2004, o benefício passou a ser integral, o que justifica o aumento da participação da categoria renúncia de receita no total de refeições servidas. No primeiro ano que surgiu, a categoria renúncia de receita absorveu $0,96 \%$ do total das refeições servidas e, em 2006, esse percentual passou para 7,67\%.

Em 2000, os bolsistas (grupos I e II) representavam 46,71\% do total de refeições servidas, em 2006, esse percentual passou para 38,70\%, uma redução de $8,02 \%$, com predominância do grupo I, que reduziu 9,59\%, enquanto os bolsistas do grupo II aumentaram 1,58\%. O grupo III (servidor e aluno sem bolsa) destaca-se em quantidade de refeições

\footnotetext{
${ }^{1} \mathrm{O}$ grupo renúncia de receita é formado por usuários beneficiados com o subsídio integral do valor da refeição. Para estes usuários o preço é igual a zero e o benefício alcança usuários internos e externos, como por exemplo, os servidores do RU, alguns servidores da IFES, alunos dos cursos de extensão, entre outros.
}

Rev. GUAL., Florianópolis, v.4, n. 2, p.01-28, mai/ago. 2011 


\section{ANÁLISE DOS RECURSOS PÚBLICOS APLICADOS NO RESTAURANTE UNIVERSITÁRIO DE UMA INSTITUIÇÃO FEDERAL DE ENSINO SUPERIOR}

servidas em todos os anos, uma vez que a participação percentual oscilou entre $49 \%$ e $58 \%$ no total de refeições servidas.

Tabela 2 - Quantidade de refeições servidas de 2000 a 2006

\begin{tabular}{lccccccccc}
\hline \multicolumn{10}{c}{ Quantidade de Refeições Servidas } \\
Anos & $\begin{array}{c}\text { Grupo } \\
\text { I }\end{array}$ & $\begin{array}{c}\text { Grupo } \\
\text { II }\end{array}$ & $\begin{array}{c}\text { Grupo } \\
\text { III }\end{array}$ & $\begin{array}{c}\text { Visitantes } \\
\text { Pessoal } \\
\text { RU }\end{array}$ & $\begin{array}{c}\text { Eventos } \\
\text { Total de } \\
\text { Pagantes }\end{array}$ & $\begin{array}{c}\text { Renúncia } \\
\text { de receita }\end{array}$ & $\begin{array}{c}\text { Total de } \\
\text { Refeições }\end{array}$ \\
2000 & 97.103 & 36.119 & 140.663 & 4.414 & 6.890 & - & 285.189 & - & 285.189 \\
2001 & 54.120 & 16.679 & 102.799 & 287 & 2.174 & - & 176.059 & - & 176.059 \\
2002 & 149.605 & 55.904 & 260.112 & - & 4.497 & - & 470.118 & - & 470.118 \\
2003 & 161.182 & 66.816 & 322.116 & - & 1.581 & 17.513 & 569.208 & 5.525 & 574.733 \\
2004 & 128.641 & 61.748 & 290.202 & - & 616 & 504 & 481.711 & 28.913 & 510.624 \\
2005 & 125.078 & 54.780 & 229.997 & 4.868 & - & - & 414.723 & 31.903 & 446.626 \\
2006 & 178.575 & 104.001 & 377.589 & 10.270 & - & 3.780 & 674.215 & 56.025 & 730.240 \\
\hline
\end{tabular}

Fonte: Elaboração própria, com base em informações do RU.

\section{Receita gerada pelo restaurante}

A receita é formada pela venda de tíquetes e créditos diretamente lançados na carteirinha de estudante ou no crachá do servidor que dão direito à refeição. Os tíquetes ou créditos não têm prazo de validade, podendo ser utilizados a qualquer tempo, de um semestre para o outro ou mesmo de um ano para o outro e, quando não utilizados e devolvidos, o valor pago é prontamente ressarcido.

A receita arrecadada pelo Restaurante cresceu 113,02\% (Tabela 3), se comparado 2000 com 2006. Observa-se que em todos os anos analisados, o grupo III (servidor e aluno sem bolsa) teve participação significante na formação da receita.

Tabela 3 - Receita do RU - 2000-2006 (R\$)

\begin{tabular}{cccccccc}
\hline Ano & $\begin{array}{c}\text { Grupo } \\
\text { I }\end{array}$ & $\begin{array}{c}\text { Grupo } \\
\text { II }\end{array}$ & $\begin{array}{c}\text { Grupo } \\
\text { III }\end{array}$ & Visitantes & $\begin{array}{c}\text { Pessoal } \\
\text { RU }\end{array}$ & Eventos & $\begin{array}{c}\text { Arrecadação } \\
\text { Total }\end{array}$ \\
2000 & 80.396 & 59.808 & 582.301 & 25.582 & 7.314 & - & 755.401 \\
2001 & 41.467 & 25.559 & 393.829 & 1.540 & 4.100 & - & 466.495 \\
2002 & 105.129 & 78.568 & 913.908 & - & 5.776 & - & 1.103 .381 \\
2003 & 94.560 & 78.397 & 944.872 & - & 2.125 & 44.983 & 1.164 .938 \\
2004 & 71.485 & 68.625 & 806.308 & - & 907 & 411 & 947.737 \\
2005 & 65.398 & 57.285 & 601.281 & 25.453 & - & - & 749.417 \\
2006 & 90.833 & 105.801 & 960.312 & 52.239 & - & 17.370 & 1.226 .556 \\
\hline
\end{tabular}

Fonte: Elaboração própria, com base nos dados do RU. Valores atualizados com base no INPC-IBGE para dezembro de 2006.

Rev. GUAL., Florianópolis, v.4, n. 2, p.01-28, mai/ago. 2011 


\section{ANÁLISE DOS RECURSOS PÚBLICOS APLICADOS NO RESTAURANTE UNIVERSITÁRIO DE UMA INSTITUIÇÃO FEDERAL DE ENSINO SUPERIOR}

\section{Custo da mão de obra}

Quanto ao custo da mão de obra, a série histórica mostra a tendência de substituição de servidores permanentes por prestadores de serviços (figura 1). Ao comparar 2000 com 2006 verifica-se que a despesa de pessoal reduziu 4\%; entretanto a despesa com os servidores do quadro permanente reduziu em $33 \%$, e a despesa com os prestadores de serviços aumentou $428 \%$.

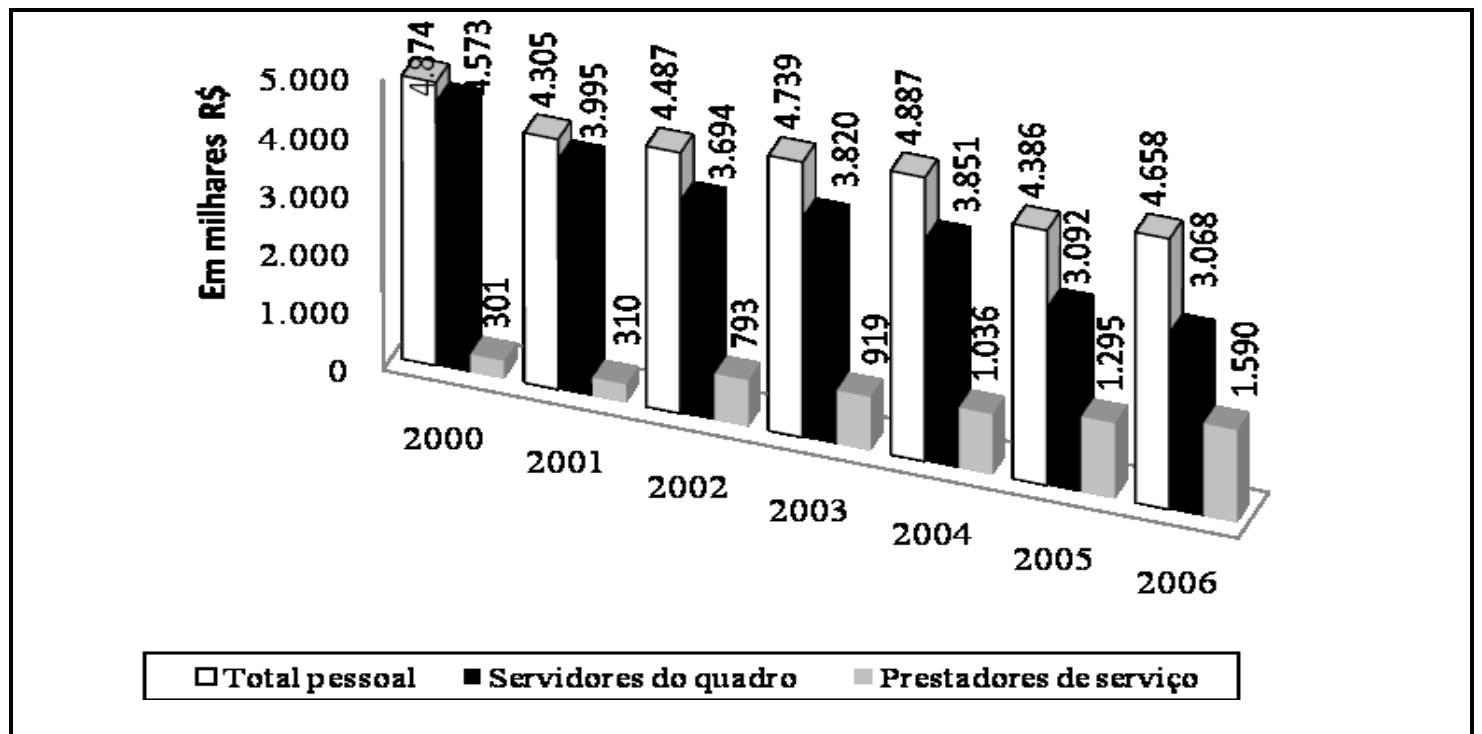

Figura 1 Evolução da despesa de pessoal total, servidores do quadro e prestadores de serviços - 2000 a 2006.

Fonte: Elaboração própria, com base em informações do RU. Valores atualizados com base no INPC-IBGE para dezembro de 2006.

\section{Material de consumo}

Dentro do grupo material de consumo, os custos variáveis diretos (excluída a mão de obra direta) se destacam por apresentarem valores elevados e as maiores variações no período. Observa-se que o item de maior despesa é carnes e peixes, seguido dos gêneros alimentícios e dos hortifrutigranjeiros.

Embora as carnes e peixes apresentem preços elevados em relação aos outros itens, a variação, de 2000 comparada com 2006, foi de 119\%; já os gêneros alimentícios tiveram variação negativa de $5 \%$. O que chama a atenção é a variação dos hortifrutigranjeiros de $266 \%$, ou seja, em 2000 gastava-se R $\$ 84.477$ mil na compra desse item; em 2006, o custo foi de R 308.879 mil. Como conseqüência, a participação das carnes e peixes no custo variável

Rev. GUAL., Florianópolis, v.4, n. 2, p.01-28, mai/ago. 2011 


\section{ANÁLISE DOS RECURSOS PÚBLICOS APLICADOS NO RESTAURANTE UNIVERSITÁRIO DE UMA INSTITUIÇÃO FEDERAL DE ENSINO SUPERIOR}

em 2000 era de 49\%, em 2006 passou para 57\%. Os gêneros alimentícios participavam com $39 \%$, no último ano participaram com $19 \%$, já os hortifrutigranjeiros que participavam com $12 \%$ em 2000, passaram para $24 \%$ em 2006.

Cabe ainda destacar que, antes de 2003, as carnes eram adquiridas em peças inteiras; mas, por falta de açougueiro, a partir dessa época passaram a serem adquiridos os pedaços já cortados, prontos para o preparo, o que elevou o valor da compra.

\section{Depreciação}

O cálculo da depreciação é feito por uma diretoria da IFES. É aplicada da taxa de $10 \%$ ao ano para os bens móveis, ou seja, dez anos de vida útil e, 2\% ao ano para os bens imóveis, isto é, cinqüenta anos de vida útil.

\section{Energia elétrica}

Até o mês de março de 2005, a universidade era isenta do pagamento de energia elétrica e água e esgoto; assim, esses gastos só foram incorporados ao resultado do RU a partir do mês de abril daquele ano.

Anterior à cobrança desses gastos não havia na universidade preocupação com os desperdícios; no entanto, a partir da exigência do pagamento surgiu a necessidade de um plano de racionalidade. Diante disso, criou-se uma comissão para conservação de energia com o objetivo de monitorar o consumo e os custos com o fornecimento de energia elétrica no campus universitário.

O RU possui uma caldeira elétrica para a geração de vapor para a cozinha. Existe um plano para substituir a energia elétrica que abastece a caldeira por fonte de energia alternativa.

Atualmente, a universidade possui um sistema de monitoração de energia elétrica instalado no Restaurante, denominado de RU Caldeiras. O objetivo é acompanhar o consumo e os custos de energia da caldeira. O consumo de energia da caldeira RU, em 2006, foi de R\$ 470.593 mil. Contudo, além da caldeira, é fornecido energia para o restante do Restaurante. Já o custo da energia do prédio do RU foi de R\$ 63.015 mil em 2006. Sendo assim, o custo total do consumo de energia elétrica do RU foi de R\$ 533.608 mil neste ano.

Rev. GUAL., Florianópolis, v.4, n. 2, p.01-28, mai/ago. 2011 


\section{ANÁLISE DOS RECURSOS PÚBLICOS APLICADOS NO RESTAURANTE UNIVERSITÁRIO DE UMA INSTITUIÇÃO FEDERAL DE ENSINO SUPERIOR}

\section{Água e esgoto}

A mesma preocupação de racionalidade se estende para o consumo de água no RU. Até o mês de outubro de 2006, o RU compartilhava o relógio de registro de consumo de água com outras unidades. A partir disso, cada prédio passou a ter um relógio próprio. Em virtude disto, o custo do consumo de água e esgoto do prédio RU em 2005 e parte de 2006 foi calculado de acordo com a metragem quadrada de cada prédio (Tabela 4) em virtude da ausência de relógio de registro.

Tabela 4 - Custo da água e esgoto alocado ao RU - 2005 a 2006

\begin{tabular}{ccccccc}
\hline \multirow{2}{*}{ Ano } & $\begin{array}{c}\text { A } \\
\text { Valor da fatura de } \\
\text { água e esgoto }- \\
\text { Universidade }\end{array}$ & $\begin{array}{c}\text { A } \\
\text { Área dos } \\
\text { edifícios }\end{array}$ & $\begin{array}{c}\text { C } \\
\text { Área do } \\
\text { RU }\end{array}$ & A $\div$ B $\times$ C & $\begin{array}{c}\text { Valor da } \\
\text { fatura de água } \\
\text { e esgoto - RU }\end{array}$ & Total RU \\
2005 & $\mathbf{R}$ & $\mathbf{m}^{\mathbf{2}}$ & $\mathbf{m}^{\mathbf{2}}$ & $\mathbf{R}$ & $\mathbf{R}$ & $\mathbf{R}$ \\
2006 & 4.973 .536 & 197.404 & 6.574 & 99.025 & NA & 99.025 \\
\hline
\end{tabular}

Fonte: Elaboração própria, com os dados fornecidos pela PRC. Valores atualizados para dez. 2006 com base no INPC- IBGE.

\section{Custos indiretos}

Representam os custos não estão diretamente ligados ao RU, referente a atividades desenvolvidas por outras áreas da universidade tais como: elaboração da folha de pagamento, compras, suporte de informática, dentre outros. Essas despesas são incluídas na apuração de resultado do RU a partir de 2003, pois só a partir daquele ano passou-se a apurar os custos dessas áreas.

Em seguida serão apresentados, detalhadamente, os custos dos serviços prestados por outras unidades.

A manutenção e conservação da infra-estrutura da universidade são feitas por uma unidade específica da instituição. Calculou-se a parcela do custo desta unidade referente aos serviços prestados ao RU, usando a área no Campus ocupada pelo restaurante. A área total do Campus possui $3.950 .579 \mathrm{~m}^{2}$, o Restaurante ocupa $6.574 .08 \mathrm{~m}^{2}$ (Tabela 5). 


\section{ANÁLISE DOS RECURSOS PÚBLICOS APLICADOS NO RESTAURANTE UNIVERSITÁRIO DE UMA INSTITUIÇÃO FEDERAL DE ENSINO SUPERIOR}

Tabela 5 - Parcela do Custo de Manutenção e Conservação da Infra-estrutura alocada ao RU - 2003 a 2006

\begin{tabular}{lcccc}
\hline Ano & A & B & C & \\
& $\begin{array}{c}\text { Custo Manutenção e } \\
\text { Conservação }\end{array}$ & $\begin{array}{c}\text { Área total do } \\
\text { Campus }\end{array}$ & $\begin{array}{c}\text { Área do RU } \\
\mathbf{m}^{\mathbf{2}}\end{array}$ & $\begin{array}{c}\mathbf{m}^{\mathbf{2}} \\
2003\end{array}$ \\
$\mathbf{R}$ & 21.184 .970 & 3.950 .579 & $6.574,08$ & $\mathbf{R} \mathbf{S}$ \\
2004 & 23.819 .299 & 3.950 .579 & $6.574,08$ & 35.253 \\
2005 & 25.739 .010 & 3.950 .579 & $6.574,08$ & 42.637 \\
2006 & 29.280 .502 & 3.950 .579 & $6.574,08$ & 48.725 \\
\hline
\end{tabular}

Fonte: Elaboração própria, com os dados internos da IFES.

Valores atualizados para dezembro de 2006 com base no INPC- IBGE.

$\mathrm{O}$ custo da área de recursos humanos alocado ao RU foi apurado com base na quantidade de servidores do Restaurante constantes nas folhas de pagamentos elaboradas por esta secretaria (Tabela 6). Denota-se que o aumento de 108\%, se comparado 2005 com 2006, deve-se ao acréscimo de $68 \%$ no número de funcionários alocados no restaurante.

Tabela 6 - Parcela do custo da SRH alocada ao RU - 2003 a 2006

\begin{tabular}{ccccc}
\hline Ano & $\begin{array}{c}\text { A } \\
\text { Custo SRH }\end{array}$ & $\begin{array}{c}\text { B } \\
\text { Servidores, Prestadores, } \\
\text { estagiários da Universidade }\end{array}$ & $\begin{array}{c}\text { Cervidores, Prestadores, } \\
\text { estagiários do RU }\end{array}$ & $\mathrm{A} \div \mathrm{B} \times \mathrm{C}$ \\
& $\mathbf{R} \$$ & $\mathbf{u n}$ & $\mathbf{\text { un }}$ & $\mathbf{R}$ \\
2003 & 5.853 .431 & 4.339 & 81 & 109.271 \\
2004 & 6.620 .116 & 4.119 & 82 & 131.792 \\
2005 & 7.538 .604 & 4.516 & 79 & 131.875 \\
2006 & 8.874 .591 & 4.298 & 133 & 274.621 \\
\hline
\end{tabular}

Fonte: Elaboração da autora, com os dados fornecidos pela área de Recursos Humanos Valores atualizados para dezembro de 2006 com base no INPC- IBGE.

Existe uma diretoria responsável pelas compras de materiais de consumo e permanente da Universidade. O custo desta unidade foi alocado ao RU utilizou como base a quantidade de bens incorporados ao ativo permanente em cada período (Tabela 7). Em 2005, não houve incorporações ao ativo permanente do RU. 
Tabela 7 -Custo de Compras de Materiais de Consumo e Permanente alocada ao RU 2003 a 2006

\begin{tabular}{ccccc}
\hline Ano & $\begin{array}{c}\text { A } \\
\text { Custo Material de } \\
\text { Consumo e } \\
\text { Permanente }\end{array}$ & $\begin{array}{c}\text { B } \\
\text { Total de bens } \\
\text { incorporados pela } \\
\text { Universidade }\end{array}$ & $\begin{array}{c}\text { C } \\
\text { Total de Bens } \\
\text { incorporados pelo RU }\end{array}$ & A $\div$ B $\times \mathrm{C}$ \\
2003 & $\mathbf{R}$ & $\mathbf{u n}$ & $\mathbf{u n}$ & $\mathbf{R}$ \\
2004 & 2.636 .277 & 6.501 & 92 & 23.156 \\
2006 & 1.934 .735 & 4.842 & 5 & 2.768 \\
\hline
\end{tabular}

Fonte: Elaboração da autora, com os dados da IFES

Valores atualizados para dezembro de 2006 com base no INPC- IBGE.

A parcela do custo da área de informática incorporada ao RU foi alocada com base nos pontos lógicos instalados. Ou seja, o total do custo da área de informática foi dividido pelo total de pontos lógicos instalados na universidade, em seguida multiplicou-se o resultado pela quantidade de pontos instalados no Restaurante (Tabela 8).

Tabela 8 - Parcela do Custo de Informática alocada ao RU - 2003 a 2006

\begin{tabular}{|c|c|c|c|c|}
\hline Ano & $\begin{array}{c}\text { A } \\
\text { Custo } \\
\text { Informática }\end{array}$ & $\begin{array}{c}\text { B } \\
\text { Total de pontos lógicos } \\
\text { instalados na Universidade }\end{array}$ & $\begin{array}{l}\text { C } \\
\text { Total de pontos lógicos } \\
\text { instalados no RU }\end{array}$ & $\mathrm{A} \div \mathrm{B} \times \mathrm{C}$ \\
\hline & $\mathbf{R S}$ & un & un & RS \\
\hline 2003 & 2.827 .679 & 5.057 & 11 & 6.151 \\
\hline 2004 & 2.870 .962 & 5.057 & 11 & 6.245 \\
\hline 2005 & 3.399 .234 & 5.583 & 11 & 6.697 \\
\hline 2006 & 3.609 .964 & 6.395 & 11 & 6.209 \\
\hline
\end{tabular}

Fonte: Elaboração da autora, com os dados fornecidos pela IFES

Valores atualizados para dezembro de 2006 com base no INPC- IBGE.

\section{Análise do desempenho financiero}

O RU apresentou déficit em todos os anos analisados, evidenciando dependência financeira de recursos do Tesouro e de recursos próprios gerados na instituição para cumprimento das obrigações. A apuração do resultado mostra as despesas/custos acumulados no valor de $\mathrm{R} \$ 47,6$ milhões, enquanto a receita auferida com a venda da refeição é de $\mathrm{R} \$ 6,4$ milhões, o que resulta no déficit acumulado de $\mathrm{R} \$ 41,2$ milhões no período. A série histórica permitiu a análise, de forma detalhada, do comportamento do resultado gerado (Apêndice A).

Rev. GUAL., Florianópolis, v.4, n. 2, p.01-28, mai/ago. 2011 


\section{ANÁLISE DOS RECURSOS PÚBLICOS APLICADOS NO RESTAURANTE UNIVERSITÁRIO DE UMA INSTITUIÇÃO FEDERAL DE ENSINO SUPERIOR}

Em 2000, o restaurante funcionou 107 dias e foram servidas 285.189 refeições, sendo 133.222 para os bolsistas. Em média foram produzidas 2.665 refeições diárias ao custo unitário de $\mathrm{R} \$ 20,76$ e vendidas ao preço médio de $\mathrm{R} \$ 2,65$, gerando um déficit por refeição de $\mathrm{R} \$ 18,11$.

Em 2001, foram servidas 176.059 refeições, sendo 70.779 para os beneficiários da bolsa alimentação. O Restaurante esteve aberto 80 dias no ano e serviu em média 2.201 refeições diárias ao custo unitário de $\mathrm{R} \$ 30,17$. O preço de venda médio de $\mathrm{R} \$ 2,65$, com isso, o déficit unitário gerado foi de $\mathrm{R} \$ 27,52$. A redução na quantidade produzida de $38 \%$ e o aumento no custo unitário de 51\% mostram que o custo fixo é elevado.

Em 2002, o Restaurante funcionou 203 dias, foram servidas 470.118 mil refeições, das quais 205.509 mil para os bolsistas. A quantidade média diária de refeições servidas foi de 2.316 mil. O custo unitário passou para $\mathrm{R} \$ 14,22$, redução de $53 \%$, enquanto o preço médio de venda passou para $\mathrm{R} \$ 2,35$, nesse caso, o déficit gerado por refeição foi de $\mathrm{R} \$ 11,87$.

Em 2003, o Restaurante esteve aberto 196 dias no ano e foram servidas 574.733 mil refeições, 227.998 mil para os usuários bolsistas. Nesse ano tem início o grupo "renúncia de receita" e o público pagante foi então de 569.208 mil usuários. A quantidade média diária de refeições servidas foi de 2.932 mil, ao custo unitário de $\mathrm{R} \$ 12,49$ reais. O preço médio de venda foi de $\mathrm{R} \$ 2,03$, e o déficit unitário foi de $\mathrm{R} \$ 10,47$.

Em 2004, o RU funcionou 138 dias, foram 510.624 mil refeições servidas, 190.389 mil para os usuários bolsistas, e o público pagante foi de 481.711 mil. A média diária de refeições servidas foi de 3.700 mil refeições, ao custo unitário de $\mathrm{R} \$ 14,11$, superior 13\% em relação ao ano anterior. $\mathrm{O}$ preço médio unitário de venda foi de $\mathrm{R} \$ 1,86$ e o déficit unitário apurado foi de R\$12,25.

Em 2005, o Restaurante esteve aberto 132 dias, foram servidas 446.626 mil refeições, ao custo unitário de $\mathrm{R} \$ 16,76$. A quantidade de usuários pagantes foi de 414.723 mil, e o preço médio unitário de venda foi de 1,68 reais, o que gera o déficit unitário de $\mathrm{R} \$ 15,08$.

Em 2006, o Restaurante funcionou 212 dias. Foram servidas 730.240 refeições ao custo unitário de $\mathrm{R} \$ 10,78$. O público pagante foi de 674.215 mil refeições, ao preço de venda unitário de $\mathrm{R} \$ 1,68$, o que gera o déficit unitário de $\mathrm{R} \$ 9,11$. Este resultado aponta para um déficit unitário 39,5\% menor que o ano anterior.

Rev. GUAL., Florianópolis, v.4, n. 2, p.01-28, mai/ago. 2011 


\section{ANÁLISE DOS RECURSOS PÚBLICOS APLICADOS NO RESTAURANTE UNIVERSITÁRIO DE UMA INSTITUIÇÃO FEDERAL DE ENSINO SUPERIOR}

\section{Resultado e discussão dos questionários aplicados}

A primeira parte do questionário focou na identificação do respondente, sendo assim, da amostra de 619 usuários dos serviços de alimentação oferecido pela instituição, 360 são alunos, 8 professores, 73 servidores técnicos, 173 prestadores de serviço e 5 são usuários sem vínculo com a universidade, denominado de visitante. Quanto ao gênero do sexo, 341 são homens e 278 mulheres. A maioria está na faixa dos 21 aos 25 anos (210), já que são alunos da graduação. Essa maioria representa $34 \%$ da amostra. Em segundo lugar, estão os respondentes na faixa dos 16 aos 20 anos, que representam $31 \%$. Em terceiro estão os 115 respondentes com mais de 35 anos, que representam 18\%, em quarto lugar estão na faixa dos 26 aos $30 \operatorname{anos}$ (66) com $10 \%$ de representatividade. E por fim, os que estão na faixa dos 31 aos 35 anos (42) que representam 7\% da amostra. Os 360 alunos pertencem aos cursos de Administração, Ciências Contábeis, Economia, Engenharia Mecânica, Educação Física e Pedagogia.

Quanto à assiduidade, 41\% dos respondentes fazem suas refeições no RU diariamente, $26 \%$ raramente, $25 \% 2$ a 3 vezes por semana e os respondentes que utilizam o RU de 10 a 15 vezes por mês, bem como os que utilizam de 5 a 10 vezes por quinzena representam as percentagens de $5 \%$ e $3 \%$, respectivamente, do total da amostra.

Cabe ressaltar que apenas $142(23 \%)$ respondentes são beneficiados com a bolsa alimentação, 79 pertencem ao grupo I- carentes e, 63 ao grupo II - semicarentes (Tabela 1).

Da questão 8 a 17, o respondente avalia aspectos do RU, indicando o grau de satisfação: 1- Muito insatisfeito; 2- Insatisfeito; 3- Indiferente; 4- Satisfeito; 5- Muito satisfeito.

A questão 8 está relacionada com a qualidade do alimento. A maioria dos respondentes (62\%) está satisfeita com a qualidade do alimento servido no RU, enquanto $17 \%$ dos pesquisados, são insatisfeitos; $16 \%$ são indiferentes e apenas $2 \%$ e 3\% da amostra de 619 , são muito insatisfeitos e muito satisfeitos respectivamente.

Foi verificada correlação estatisticamente significante entre a qualidade do alimento e outras questões, como por exemplo: qualidade do alimento e a variedade do cardápio $(\mathrm{r}=$ $0,461 ; \alpha=0,01)$; qualidade do alimento e o preço da refeição $(r=0,160 ; \alpha=0,01)$; qualidade do alimento e o tempo de atendimento $(r=0,216 ; \alpha=0,01)$.

Rev. GUAL., Florianópolis, v.4, n. 2, p.01-28, mai/ago. 2011 


\section{ANÁLISE DOS RECURSOS PÚBLICOS APLICADOS NO RESTAURANTE UNIVERSITÁRIO DE UMA INSTITUIÇÃO FEDERAL DE ENSINO SUPERIOR}

A questão 9 também é relacionada com a comida e verifica a opinião do respodente sobre a variedade do cardápio oferecido diariamente no RU. Denota-se que, pouco mais de um 1/3 estão insatisfeitos com a variedade do cardápio; na mesma medida anterior, estão os respondentes satisfeitos que representam $38 \%$ e $34 \%$ da amostra, respectivamente; já os que responderam ser indiferentes são 116 pessoas, ou seja, 19\%; os muito insatisfeitos e os muito satisfeitos representam $8 \%$ e $1 \%$ da amostra, respectivamente

O resultado da pesquisa de avaliação do RU realizada por Caixeta e Cunha (1994), revelou que a qualidade da comida foi considerada sem grande importância, dentro dos motivos que levavam as pessoas a fazerem suas refeições no RU diariamente.

A análise estatística da relação da variedade do cardápio com outras questões evidencia correlação significante entre: variedade do cardápio e o tempo de atendimento $(\mathrm{r}=$ $0,137 ; \alpha=0,01)$; variedade do cardápio e a localização do restaurante $(\mathrm{r}=0,162 ; \alpha=0,01)$.

A abordagem na questão 10 é quanto ao tempo de espera para o atendimento, o resultado da pesquisa mostra que $30 \%$ são insatisfeitos com o tempo de espera, outros $30 \%$ responderam estar satisfeitos. Enquanto $20 \%$ dos pesquisados responderam estar muitos insatisfeitos, os que responderam ser indiferentes são $19 \%$ e, $1 \%$ responderam estar muito satisfeitos. Foi observada correlação positiva entre o tempo de espera e a localização do restaurante $(\mathrm{r}=0,107 ; \alpha=0,01)$.

$\mathrm{O}$ restaurante abre às onze horas e encerra às quatorze horas para o almoço e das dezessete às dezenove horas para o jantar, de segunda a sexta-feira. A questão 11 busca saber se o horário é favorável aos usuários pesquisados. Os respondentes satisfeitos representam mais da metada da amostra (56\%), enquanto $21 \%$ estão muito satisfeitos. Apenas $9 \%$ responderam não estar satisfeitos e 3\% estão muito insatisfeitos. Os indiferentes representam $11 \%$ da amostra. A análise da relação estatística mostrou que o horário de funcionamento tem correlação positiva com localização do restaurante $(\mathrm{r}=0,216 ; \alpha=0,01)$; com qualidade do alimento $(r=0,213 ; \alpha=0,01)$; com o preço da refeição $(r=0,199 ; \alpha=0,01)$.

Quanto à adequação das instalações do RU, a questão 12 tem o objetivo de verificar se os usuários estão satisfeitos ou não com as instalações. De acordo com os resultados, 57\% respondentes estão satisfeitos, enquanto, $1 / 4$ são indiferentes. Os respodentes insatisfeitos são $11 \%$, enquanto os muito satisfeitos são $6 \%$ e os muito insatisfeitos são $1 \%$ da amostra. A análise estatística da adequação das instalações com outras questõs revelou correlação 


\section{ANÁLISE DOS RECURSOS PÚBLICOS APLICADOS NO RESTAURANTE UNIVERSITÁRIO DE UMA INSTITUIÇÃO FEDERAL DE ENSINO SUPERIOR}

positiva significativa com a conservação e manutenção do ambiente $(\mathrm{r}=0,436 ; \alpha=0,01)$, com localização do restaurante $(\mathrm{r}=0,355 ; \alpha=0,01)$, com o horário de funcionamento $(\mathrm{r}=$ $0,247 ; \alpha=0,01)$.

$\mathrm{Na}$ questão 13 buscou-se verificar a opinião dos usuários quanto à conservação e à manutenção do ambiente. A maioria dos respondentes (58\%) estão satisfeitos, $10 \%$ estão muito satisfeitos. 115 respondentes, representando $19 \%$ da amostra de 619 , são indiferentes à conservação e manutenção do RU, enquanto $12 \%$ responderam estar insatisfeitos e, $1 \%$ muito insatisfeitos. A análise da relação da conservação e manutençãodo ambiente com outras questões revelou correlação positiva com o preço da refeição $(r=0,183 ; \alpha=0,01)$ e com a qualidade do alimento $(\mathrm{r}=0,176 ; \alpha=0,01)$.

$\mathrm{Na}$ questão 14, o intuito era verificar se o a localização do restaurante era um empecilho para o usuário. No entanto, $59 \%$ responderam estar satisfeitos, $22 \%$ estão muito satisfeitos, enquanto $14 \%$ são indiferentes. Apenas 4\% estão insatisfeitos e 1\% muito insatisfeitos. Foi observada correlação positiva entre a localização do restaurante e o preço da refeição $(\mathrm{r}=0,242 ; \alpha=0,01)$; a localização do restaurante com a relação dos atendentes com os usuários $(\mathrm{r}=0,456 ; \alpha=0,01)$.

Buscou-se também captar a percepção dos usuários quanto à apresentação dos atendentes e à higiene do funcionário que lida com o alimento (questão 15.). De acordo com os resultados, $61 \%$ estão satisfeitos, $19 \%$ estão muito satisfeitos e $14 \%$ dos respondentes são indiferentes. Enquanto isso, 3\% dos respondentes estão insatisfeitos, e outros 3\% estão muito insatisfeitos. A análise estatística revelou correlação positiva da apresentação dos atendentes (higiene) com a qualidade do alimento $(\mathrm{r}=0,286 ; \alpha=0,01)$, com o preço da refeição $(\mathrm{r}=$ $0,134 ; \alpha=0,01)$, com a conservação e manutenção do ambiente $(r=0,432 ; \alpha=0,01)$, e com a relação dos atendentes com os usuários $(\mathrm{r}=0,513 ; \alpha=0,01)$.

Em continuidade à pergunta anterior, a questão16 buscou captar a relação dos usuários com os atendentes. $42 \%$ das pessoas estão satisfeitas, $34 \%$ são indiferentes. Já $12 \%$ dos usuários responderam estar insatisfeitos, enquanto $8 \%$ responderam estar muito satisfeitos, 4\% estão muito insatisfeitos. Verificou-se estatisticamente a relação dos atendentes com os usuários e com a adequação das instalações $(\mathrm{r}=0,238 ; \alpha=0,01)$, o tempo de atendimento $(\mathrm{r}=$ $0,289 ; \alpha=0,01)$, e o preço da refeição $(r=0,166 ; \alpha=0,01)$.

Rev. GUAL., Florianópolis, v.4, n. 2, p.01-28, mai/ago. 2011 


\section{ANÁLISE DOS RECURSOS PÚBLICOS APLICADOS NO RESTAURANTE UNIVERSITÁRIO DE UMA INSTITUIÇÃO FEDERAL DE ENSINO SUPERIOR}

A questão 17 questiona o que o usuário pensa do preço da refeição, já que há vários preços para a mesma refeição dependente do grupo em que o usuário se enquadra. $43 \%$ dos respondentes estão satisfeitos com o preço, $25 \%$ responderam estar muito satisfeitos, $15 \%$ estão insatisfeitos. Os indiferentes representam $11 \%$ da amostra, e os muito insatisfeitos são $6 \%$. Foi observada correlação entre o preço da refeição e a qualidade do alimento $(r=0,160$; $\alpha=0,01)$.

Já na questão 18 , fechada, foi solicitado ao respondente que indicasse as opções que na opinião dele, pudessem ser objeto de melhoria no RU. É importante destacar que nesta questão as alternativas não são exludentes, sendo assim, o respondente poderia marcar várias alternativas.

A opção que se destaca em indicações é a "variedade do cardápio" com $1 \frac{1}{4}$ dos respondentes. Observa-se que o total de respondentes que marcaram esta opção de melhoria (485) é maior que a soma dos insatisfeitos, muito insatisfeitos e os indiferentes(399) da questão 9. Pode-se, então, afirmar que, mesmo aqueles que estão satisfeitos ou muito satisfeitos, também marcaram a opção.

A segunda opção mais indicada é o "tempo de atendimento" com $20 \%$ da amostra. Nesta questão, o total de respondentes (392) que marcaram essa opção é superior ao total de respondentes insatisfeitos e muito insatisfeitos na questão 10 (309). Nesse caso os respondentes indiferentes ou mesmo os satisfeitos e muito satisfeitos podem ter marcado a opção de melhoria.

A terceira questão com mais indicações foi a "qualidade do alimento" com $16 \%$ da amostra. A quantidade de respondentes que marcaram esta opção (316) é superior à soma dos insatisfeitos, muito insatisfeitos e indiferentes (215) da questão 8. Sendo assim, mesmo aqueles que estão satisfeitos ou muito satisfeitos também indicaram esta opção de melhoria.

A "relação dos atendentes com os usuários" e o "preço da refeição" tiveram o mesmo percentual de respondentes (9\%). A quantidade de usuários que indicaram a opção de melhoria preço da refeição (184) é maior que aqueles insatisfeitos e muito insatisfeitos (97) da questão 16; então, mesmo os satisfeitos, muito satisfeitos ou indiferentes também marcaram a opção. Quanto ao preço da refeição, 183 respondentes indicaram como opção de melhoria; no entanto, na questão 17, apenas, 132 respondentes estavam insatisfeitos ou muito insatisfeitos;

Rev. GUAL., Florianópolis, v.4, n. 2, p.01-28, mai/ago. 2011 


\section{ANÁLISE DOS RECURSOS PÚBLICOS APLICADOS NO RESTAURANTE UNIVERSITÁRIO DE UMA INSTITUIÇÃO FEDERAL DE ENSINO SUPERIOR}

dessa maneira, mesmo aqueles que estão satisfeitos, muito satisfeitos ou indiferentes marcaram como opção de melhoria.

O mesmo acontece com a soma dos respondentes que marcaram a apresentação dos atendentes (higiene) como opção de melhoria (59), que é superior à soma dos insatisfeitos e muito insatisfeitos da questão 15 (36), sendo assim, os satisfeitos, muito satisfeitos ou indiferentes, também, marcaram a opção.

A "adequação das instalações" e o "horário de funcionamento" tiveram o mesmo percentual de indicações (5\%). Novamente, a soma dos respondentes que indicaram as adequações das instalações como opção de melhoria (91) é maior que a soma dos insatisfeitos e muitos insatisfeitos (76) na questão 12; assim, mesmo os satisfeitos, muito satisfeitos e os indiferentes marcaram a opção. Quanto ao horário de funcionamento, a quantidade de respondentes que indicaram-na (96) é maior que os insatisfeitos ou muito insatisfeitos (75) na questão 11, ou seja, mesmo aqueles que estão satisfeitos ou muito insatisfeitos ou mesmo indiferentes indicaram a opção.

Quanto à "conservação e manutenção do ambiente", 7\% dos respondentes indicaram como opção de melhoria. Observa-se que a soma dos respondentes que indicaram esta opção (140) é superior à soma dos insatisfeitos e muito insatisfeitos na questão 13(82); assim, podese inferir que mesmo os satisfeitos, muito satisfeitos e indiferentes, também, indicaram a opção. A opção "localização do restaurante", com indicação de 19 respondentes, que corresponde a $1 \%$ da amostra, difere da soma dos insatisfeitos e muito insatisfeitos (30) na questão 14.

Embora, na questão 18 as alternativas sejam fechadas, dois respondentes pediram para indicar, como fator de melhoria, que o restaurante oferecesse opções de suco sem açúcar, para favorecer os diabéticos

\section{Teste de hipóteses}

Admite-se como hipótese nula que as proporções das freqüências observadas são iguais às proporções das freqüências esperadas, ou seja, que as proporções divergentes não são significativas. E como hipótese alternativa considera-se que, as proporções das freqüências observadas e esperadas não são iguais, que as divergências entre as proporções são significativas.

Rev. GUAL., Florianópolis, v.4, n. 2, p.01-28, mai/ago. 2011 


\section{ANÁLISE DOS RECURSOS PÚBLICOS APLICADOS NO RESTAURANTE UNIVERSITÁRIO DE UMA INSTITUIÇÃO FEDERAL DE ENSINO SUPERIOR}

$\mathrm{H}_{0}$ : As proporções das freqüências observadas e esperadas são iguais

$\mathrm{H}_{1:}$ As proporções das freqüências observadas e esperadas não são iguais

Os resultados da análise de divergências entre as freqüências observadas e esperadas quando a amostra foi desdobrada em masculino e feminino, revelaram associações estatisticamente significativas, nas questões "apresentação dos atendentes (higiene)" e na "relação dos atendentes com os usuários" $(\mathrm{P}=0,002)$, tanto para o masculino quanto para o feminino, sendo assim, a hipótese nula é rejeitada.

Dos 341 respondentes do gênero masculino 18(5,3\%) marcaram como opção de melhoria tanto a "relação dos atendentes com os usuários" quanto a "apresentação dos atendentes (higiene)". No gênero feminino, observou-se que dos 278 respondentes 14 (5\% marcaram como opção de melhoria tanto a "relação dos atendentes com os usuários" quanto a "apresentação dos atendentes (higiene)". Contudo; dos 341 respondentes do gênero masculino, 77 (22,60\%) marcaram apenas a opção de melhoria "relação dos atendentes com os usuários", enquanto $18(5,3 \%)$ marcam apenas a opção "apresentação dos atendentes (higiene)".

Verificou-se associação estatística significativa entre as questões "preço da refeição" e "localização do restaurante" ( $\mathrm{P}=0,006)$ para o gênero masculino; neste caso a hipótese nula é rejeitada, já o gênero feminino não apresentou associação estatística significativa e a hipótese nula não é rejeitada.

Dos 341 respondentes masculinos, $6(1,8 \%)$ marcaram apenas "localização do restaurante" como opção de melhoria e 82 marcaram o "preço da refeição". Enquanto isto, 9 $(2,6 \%)$ respondentes masculinos marcaram como opção de melhoria tanto o preço da refeição quanto a localização do restaurante. O resultado mostrou que no gênero feminino 186 respondentes, que representa $66,9 \%$ dos 278 , não marcaram nenhuma das opções, mas 88 $(31,7 \%)$ respondentes femininos optaram pela melhoria do preço da refeição e $4(1,4 \%)$ optaram pelas duas opções ao mesmo tempo.

Considerando os respondentes que têm bolsa alimentação(142), foi observado associação estatística significativa entre a "qualidade do alimento" e a "variedade do cardápio" $(\mathrm{P}=0,001)$, assim a hipótese nula é rejeitada; Entretanto, para os respondentes que não têm bolsa alimentação não foi possível identificar associação estatística. Dos 


\section{ANÁLISE DOS RECURSOS PÚBLICOS APLICADOS NO RESTAURANTE UNIVERSITÁRIO DE UMA INSTITUIÇÃO FEDERAL DE ENSINO SUPERIOR}

respondentes que têm bolsa alimentação(142), 80 (56,30\%)marcaram como opção de melhoria a "qualidade do alimento" e "variedade do cardápio" ao mesmo tempo. 44 (31\%) respondentes marcaram apenas a opção "variedade do cardápio". 4 (2,8\%) respondentes marcaram apenas a "qualidade do alimento". Os demais 14 (9,9\%) não marcaram nenhuma das opções. Dos respondentes que não têm bolsa alimentação (477), 202 (42,30\%) marcaram ambas as alternativas (variedade do cardápio e a qualidade do alimento) como opções de melhoria no RU. 159 respondentes escolheram apenas a "variedade do cardápio". 30 respondentes escolheram apenas a "qualidade do alimento" e 86 não escolheram nenhuma nem outra alternativa.

Nas questões "tempo de atendimento (espera/rapidez)" e o "horário de funcionamento" a proporção dos respondentes que não têm bolsa alimentação revelou evidência de associação estatística significativa $(P=0,020)$ onde a hipótese nula é rejeitada; no entanto, os respondentes que têm bolsa alimentação não apresentaram associação significativa. Dos 142 respondentes que têm bolsa alimentação, 114 (80,3\%) optaram apenas pela alternativa "tempo de atendimento (espera/rapidez)", 12 (8,5\%)marcaram apenas a opção "horário de funcionamento". $16(11,3 \%)$ respondentes marcaram as duas opções ao mesmo tempo e $30(21,10 \%)$ não marcaram nenhuma das alternativas. Dos respondentes que não têm bolsa alimentação (477), 259 (54,30\%) marcaram apenas a alternativa "tempo de atendimento (espera/rapidez)", enquanto 35(7,3\%) respondentes optaram apenas pelo "horário de funcionamento". 33 (6,9\%) respondentes optaram pelas duas alternativas a mesmo tempo e os demais 150 (31,4\%) não escolheram nenhuma das alternativas de melhoria no RU.

\section{CONSIDERAÇÕES FINAIS}

Os resultados obtidos mostram que o RU apresenta déficit, uma vez que os recursos próprios gerados com a cobrança da refeição não são suficientes para cobrir as despesas/custos, o que evidencia dependência financeira de aporte de recursos do Tesouro Federal e recursos próprios. No período analisado, foram aplicados $\mathrm{R} \$ 41,2$ milhões, sendo que, somente em 2006, foram alocados R \$ 6,6 milhões na atividade do restaurante.

Observou-se que diversos fatores contribuem para o resultado deficitário, tais como o crescente quadro de pessoal, com destaque para a substituição de servidores do quadro (pagos pelo Tesouro) por prestadores de serviços (pagos pelos recursos gerados pela própria

Rev. GUAL., Florianópolis, v.4, n. 2, p.01-28, mai/ago. 2011 


\section{ANÁLISE DOS RECURSOS PÚBLICOS APLICADOS NO RESTAURANTE UNIVERSITÁRIO DE UMA INSTITUIÇÃO FEDERAL DE ENSINO SUPERIOR}

Instituição), a ascendência do grupo "renúncia de receita". Quando iniciou, em 2003, eram 5.525 mil refeições, em 2006 passou para 56.025 mil refeições gratuitas, o que representa 914\% de acréscimo. Além disso, as despesas com energia elétrica e água e esgoto que passaram a ser devidas em 2005, aumentaram, ainda mais, o déficit. Como exemplo disso, a utilização de caldeira "elétrica" para cocção dos alimentos, que no último ano analisado representou $88,19 \%$ do consumo de energia elétrica. Outro exemplo que contribui para o déficit é a aquisição das carnes já cortadas, ou seja, preparadas para a cocção, em lugar de pedaços inteiros.

A análise evidencia uma tendência de crescimento no déficit. Um estudo realizado com base nos dados de custo mostrou que a operação do restaurante somente seria rentável diante de mudanças estruturais. Mais ainda, uma vez que os custos variáveis unitários são superiores ao preço da refeição, tem-se a situação paradoxal onde o desempenho do restaurante, em termos de valores totais, é melhor nas férias ou nos períodos de greve. Em outras palavras, o prejuízo é menor quando o restaurante está fechado.

Uma proposta de terceirização da atividade, com um conseqüente aumento nos preços, provocou uma discussão interna sobre o assunto. Os representantes dos estudantes apresentaram informações de outras universidades onde o "custo" da refeição, representado pela divisão do material de consumo pelo número de refeições, era inferior a $\mathrm{R} \$ 3$. A discussão tomou um rumo político e o próprio Reitor retirou a discussão de pauta.

Entretanto, o problema persiste uma vez que o restaurante opera, para a grande maioria dos usuários, com margem de contribuição negativa. Além disso, denota-se que, os servidores são beneficiados em duplicidade, pagam $\mathrm{R} \$ 2,50$ pela refeição $(23,19 \%$ do custo unitário) e recebem benefício alimentação no contracheque.

Quanto à opinião dos usuários do serviço de alimentação, a maioria mostrou-se satisfeita com a qualidade do alimento servido (62\%), com a variedade do cardápio (38\%), com o preço da refeição (43\%), dentre outros.

Cabe ressaltar que, a proposta do estudo não é questionar a legitimidade do subsídio à alimentação fornecida à população da instituição, mas fornecer informações, que possam ser úteis na gestão de recursos públicos. Sendo assim, sugere-se que a pesquisa seja realizada em períodos posteriores para que seja feita a comparabilidade com o resultado ora apresentado.

Rev. GUAL., Florianópolis, v.4, n. 2, p.01-28, mai/ago. 2011 


\section{ANÁLISE DOS RECURSOS PÚBLICOS APLICADOS NO RESTAURANTE UNIVERSITÁRIO DE UMA INSTITUIÇÃO FEDERAL DE ENSINO SUPERIOR}

\section{REFERÊNCIAS}

BRASIL. Constituição: República Federativa do Brasil. Senado Federal, Brasília, 1988.

Ministério do Planejamento, Orçamento e Gestão. Secretaria de Orçamento Federal.

Orçamento da União exercício financeiro 2006. Lei $\mathrm{n}^{\circ}$ 11.306, de 16 de maio de 2006, v.5, Brasília, 2006. Disponível em:

$<$ http://www.planejamento.gov.br/orcamento/conteudo/orcamento_anteriores.htm>, Acesso em 12 jan. 2007.

BROWN, A. W.; GAMBER, C. Cost containment in higher education. The ASHE-ERIC Higher education report, v 28, n 5, 2002.

CFC.CONSELHO FEDERAL DE CONTABILIDADE. Resolução n. 750/93 - Princípios Fundamentais de Contabilidade. Disponível em:

$<$ http://www.portaldecontabilidade.com.br/nbc/res750.htm>, Acesso em 8 ago. 2007.

CRUZ, N.H.; DIAZ, M.D.M.; LUQUE, A.C. Metodologia de avaliação de custos nas universidades públicas: Economia de escala e de escopo. Revista Brasileira de Economia, v.58, n.1: 45-66,jan/mar 2004.

GIMÉNEZ M. V.; MARTÍNEZ L.J. Cost efficiency in the university: A departmental evaluation model. Economics of education review, Available online 21 September 2005.

GONZALES, K.M. O sistema de acompanhamento em compras e logística numa organização pública. Revista de Ciências Sociais e Humanas, Londrina, v.24,9-p.53-74,set.2003.

INEP.Instituto Nacional de Estudos e Pesquisas Educacionais Anísio Teixeira. Informativo ano $5, \mathrm{n}^{\mathrm{o}} 155,13$ de abr 2007.

MARQUES, F.M.P.; CORBUCCI, P.R. Fontes de financiamento das instituições federais de ensino superior: um estudo sobre a Universidade de Brasília. Texto para discussão n.999, ISSN 1415-4765, IPEA, 2003.

MARQUES, F.M.P.; VELLOSO, J.Recursos próprios da UnB, O financiamento das IFES e a reforma da educação superior. Educ.Soc.,Campinas, v.26, n 91, p 655-680, Maio/Ago.2005.

MARTINS, G.A. Estudo de caso: uma estratégia de pesquisa. São Paulo, Atlas, 2006.

MORGAN, B. F. A determinação do custo do ensino na educação superior: o caso da Universidade de Brasília. Dissertação de Mestrado.UnB, Brasília, 2004.

MOURA, A.R. Princípios contábeis aplicados à contabilidade governamental: uma abordagem comparativa Brasil-Estados Unidos. Dissertação de Mestrado. UnB, Brasília, $2003 a$. 
MOURA, J.F.M. O sistema de contabilidade do governo federal na mensuração dos custos dos programas de governo e das unidades gestoras. Dissertação de Mestrado. UnB, Brasília, 2003b.

PSACHAROPOULOS, G. Economics of education: A Research Agenda. Economics of education review, v.15 n .4. pp. 339-344, 1996.

QUINTANA, A.C. ; SAURIN V. Fontes de financiamento e despesas por categorias econômicas no ensino superior: Uma análise comparativa em três universidades federais da região sul. Revista de Ciência da Administração, v.7, n.13,p.49-66,jan./julho 2005.

SGUISSARDI, V. Universidade Pública Estatal: entre o público e o privado/mercantil. Educação \& Sociedade, Campinas, vol. 26, n.90, p. 191-222, jan./abr.2005.

STEVENSON, W. J. Estatística Aplicada à Administração. São Paulo: Ed. Harbra, 2001. 
APÊNDICE A - DEMONSTRAÇÃO DE RESULTADO DO RU - 2000 A 2006

\begin{tabular}{|c|c|c|c|c|c|c|c|c|}
\hline DESCRIÇÃO & 2000 & 2001 & 2002 & 2003 & 2004 & 2005 & 2006 & Acumulado \\
\hline RECEITA & 755.401 & 466.495 & 1.103 .381 & 1.164 .938 & 947.737 & 749.416 & 1.226 .556 & 6.413 .924 \\
\hline $\begin{array}{l}\text { DESPESAS/CUSTOS } \\
\text { OPERACIONAIS }\end{array}$ & 5.920 .578 & 5.311 .799 & 6.685 .063 & 7.180 .043 & 7.203 .610 & 7.484 .525 & 7.875 .590 & 47.661 .208 \\
\hline CUSTO DA MÃO DE OBRA & 4.874 .121 & 4.693 .764 & 5.374 .725 & 5.002 .953 & 5.193 .379 & 4.508 .965 & 4.657 .670 & 34.305 .577 \\
\hline Do Quadro Permanente & 4.672 .651 & 4.500 .844 & 4.605 .453 & 4.218 .665 & 4.315 .189 & 3.546 .266 & 3.257 .285 & 29.116 .353 \\
\hline Prestadores de Serviço & 201.470 & 192.919 & 769.273 & 784.288 & 878.191 & 962.698 & 1.400 .386 & 5.189 .225 \\
\hline MATERIAIS DE CONSUMO & 940.538 & 592.400 & 1.279 .215 & 1.821 .710 & 1.649 .026 & 1.740 .566 & 1.895 .556 & 9.919 .011 \\
\hline DEPRECIAÇÃO & & & & 136.917 & 139.356 & 140.713 & 173.511 & 590.497 \\
\hline TELEFONE & & & & 5.978 & 8.245 & 7.506 & 8.755 & 30.484 \\
\hline ENERGIA ELÉTRICA & - & - & - & - & - & 703.751 & 533.608 & 1.237 .359 \\
\hline ÁGUA E ESGOTO & - & - & - & - & - & 99.025 & 196.992 & 296.017 \\
\hline SERVIÇOS DE TERCEIROS PJ & 105.918 & 25.634 & 31.122 & 38.654 & 33.162 & 102.594 & 65.431 & 402.515 \\
\hline CUSTOS INDIRETOS & & & & 173.831 & 180.442 & 181.405 & 344.067 & 879.745 \\
\hline DÉFICIT - TOTAL & $(5.165 .177)$ & $(4.845 .303)$ & $(5.581 .682)$ & $(6.015 .105)$ & $(6.255 .873)$ & $(6.735 .109)$ & $(6.649 .034)$ & $(41.247 .284)$ \\
\hline Quantidade de refeições servidas & 285.189 & 176.059 & 470.118 & 574.733 & 510.624 & 446.626 & 730.240 & 730.240 \\
\hline Custo unitário & 20,76 & 30,17 & 14,22 & 12,49 & 14,11 & 16,76 & 10,78 & 10,78 \\
\hline Preço médio unitário & 2,65 & 2,65 & 2,35 & 2,03 & 1,86 & 1,68 & 1,68 & 1,68 \\
\hline Déficit unitário & $(18,11)$ & $(27,52)$ & $(11,87)$ & $(10,47)$ & $(12,25)$ & $(15,08)$ & $(9,11)$ & $(9,11)$ \\
\hline Quantidade de dias de funcionamento & 107 & 80 & 203 & 196 & 138 & 132 & 212 & 212 \\
\hline
\end{tabular}

Fonte: Própria, com base nas informações do RU, SIAFI e outros órgãos da IFES.

Valores atualizados pelo INPC-IBGE médio para dezembro de 2006. 


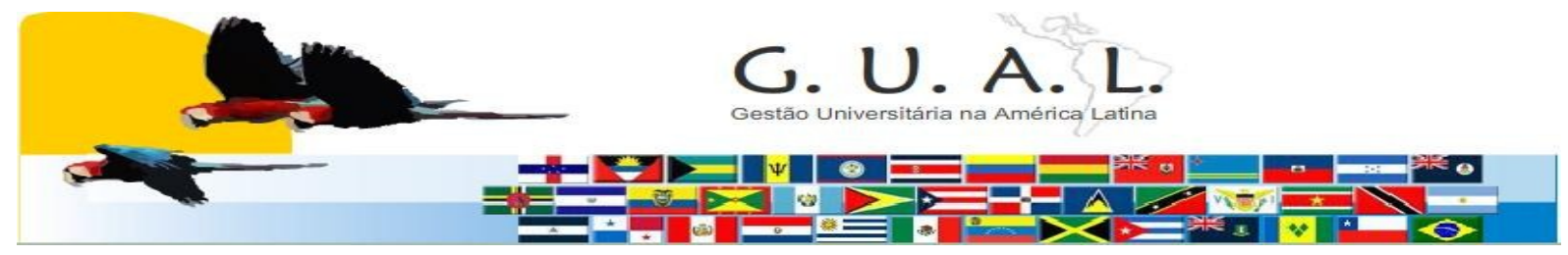

ISSN 1983-4535

\title{
APPLIED ANALYSIS OF PUBLIC RESOURCES AT THE UNIVERSITY RESTAURANT OF A FEDERAL COLLEGE INSTITUTION
}

\author{
Francisca Aparecida de Souza, Mestre \\ Universidade de Brasília \\ fsouza@unb.br \\ César Augusto Tiburcio Silva, Doutor \\ Universidade de Brasília \\ cesartiburcio@unb.br
}

\begin{abstract}
The purpose of this study is the analysis of public resources applied to the University Restaurant for a Federal College Institution and the users' opinions of the food service. It is a case study, which involved documentary research reports of the institution's information systems and information system of the Financial Administration of the Federal Government. It was found and analyzed the financial results, the unit cost of the meal, the operational evolution of the restaurant and verification of user satisfaction. The results show a deficient activity which shows financial dependence on federal public resources, in addition to internally generated by the institution. Over this period, $\mathrm{R} \$ 42.1$ million have been applied in the restaurant, and the revenue generated by the restaurant was $\mathrm{R} \$ 6.4$ million. The feedback from users, verified by a questionnaire, shows the most satisfaction in relation to "quality food" and "price of the meal." The statistical test results of the chi-square $\chi^{2}$, considering that the respondents are granted with meal allowance, denotes the association significant $(\mathrm{P}=$ 0.001 ) between the "quality food" and "variety of the menu."
\end{abstract}

Keywords: Public resources. University restaurant. Users. 